\title{
Considerações fenomenológicas sobre o conceito de endogeneidade na esquizofrenia
}

\author{
Melissa Garcia Tamelini ${ }^{1}$
}

\begin{abstract}
Resumo: O presente artigo discute a validade do conceito de endogeneidade, tal como apresentado previamente por Hubertus Tellenbach, na esquizofrenia. Inicialmente, as características inerentes ao fenômeno endógeno, tais como perda de ritmos, alteração da cinese vital e reversibilidade, serão revistas e analisadas dentro de uma perspectiva essencialista, cara à proposta fenomenológica. Em um segundo momento, tal essência endógena será colocada a prova no curso da esquizofrenia, em diálogo estreito com o conceito de estrutura psíquica. Finalmente, serão tecidas algumas considerações preliminares sobre a importância da incorporação de tal noção de endogeneidade nos estudos psicopatológicos da esquizofrenia.
\end{abstract}

Palavras-chave: Esquizofrenia, Endogeneidade, Essências, Psicopatologia fenomenológica.

\section{Phenomenological considerations of the concept of endogeneity in schizophrenia}

\begin{abstract}
The present article discusses the validity of the concept of endogeneity, as previously presented by Hubertus Tellenbach, in schizophrenia. At first, the characteristics inherent to the endogenous phenomenon, such as loss of rhythms, change to vital kinesis and reversibility will be reviewed and analysed within the essentialist perspective inside the phenomenological approach. At a second moment, that endogenous essence will be tested in light of the clinical course of schizophrenia, in a close dialogue with the concept of psychic structure. At last, some preliminary considerations will be made about the importance of integrating this particular notion of endogeneity into the studies of schizophrenia.
\end{abstract}

Keywords: Schizophrenia, Endogeneity, Essences, Phenomenological Psychopathology.

\footnotetext{
${ }^{1}$ Médica Psiquiatra - Membro da Sociedade Brasileira de Psicopatologia Fenômeno-Estrutural e Médica assistente do Instituto de Psiquiatria do Hospital das Clínicas da Faculdade de Medicina da Universidade de São Paulo. E-mail: melissa@fenomenoestrutural.com.br.
} 
Considerações fenomenológicas sobre o conceito de endogeneidade na esquizofrenia

A psicopatologia fenomenológica é uma vertente polifônica que encontra coesão enquanto método de investigação do seu objeto. Seu corpo de conhecimento nasce da experiência proximal e sem intermediários com o fato psicopatológico e, por se constituir um pouco hermético, oferta-se, ele próprio, como ponto de partida para novos esforços conceituais.

Em relação à esquizofrenia, psicose marcada pela diversidade fenomênica e pela heterogeneidade evolutiva, indiscutivelmente mais intrincada à biografia que a mania e a melancolia, a tradição fenomenológica examina-a, grosso modo, através de duas linhas de análise, não propriamente excludentes. A primeira delas interessa-se em revelar a morphé esquizofrênica por meio de uma descrição fenomenológica-eidética (Blankenburg, 2013, p. 52). À patologia vincula-se a primazia de uma forma temporoespacial típica e impessoal, um desenho estrutural próprio, uma espécie de selo de especificidade que facultaria pretensões diagnósticas (Messas, 2012). Como modificação basal ou nuclear da esquizofrenia, para citar duas grandes contribuições da literatura clássica, Minkowski postula a "ruptura do contato vital com a realidade" (Minkowski, 2000) e Blankenburg, a "perda da evidência natural" (Blankenburg, 2013). Esta última faz referência à crise das "evidências implicitamente pré-dadas e presentes no homem normal - que lhe permitem o exercício não problemático da vida cotidiana e da experiência natural" (Blankenburg, 2013) que, mais que uma perda, remete a uma "desproporção que conduz à autonomização de uma possibilidade imanente ao ser humano" (Tatossian, 2006, p. 90). Para caracterizar o modo essencial de ser 
esquizofrênico, presente não apenas nas formas pauci-sintomáticas, as escolhidas por Blankenburg para o estudo, mas também nas apresentações produtivas (Blankenburg, 2013), esquadrinha os fundamentos do common sense, estudando-o em relação à sua articulação com o mundo, à temporalização, à constituição do si-mesmo e da intersubjetividade.

A segunda linha de investigação tem como partidário de maior destaque Binswanger e, como maior produto, a obra Esquizofrenia (Binswanger, 1957). Os cinco casos lá agrupados compartilham uma extensa pesquisa factual, apresentações polimórficas da patologia e disparidade de desfechos clínicos. Ao privilegiar a perspectiva histórica, Binswanger pôde ilustrar a evolução da estrutura esquizofrênica e, através da sua projeção em trajetórias individuais, revelar esboços de mundo e comportamentos biográficos que lhe são próprios.

A "forma esquizofrênica" é vista de modo conciso por Binswanger, sobretudo na parte introdutória do livro, escrita posteriormente por ocasião da publicação da obra (Binswanger, 1957). Nos casos em questão, ela fica implícita em passagens que mencionam um estreitamento das possibilidades existenciais e uma inautenticidade do devir, dados pela desintegração da temporalidade vivida. Por sua vez, os autores da perspectiva essencialista também não privilegiam a visada longitudinal. Minkowski, de modo ilustrativo, vale-se de vinhetas clínicas para postular a fratura do contato vital e, ainda que não refute a vertente histórica, abstém-se de discutir a sua implantação no caso individual (Minkowski, 2000; 2005). 
Considerações fenomenológicas sobre o conceito de endogeneidade na esquizofrenia

Tanto a perspectiva formal como a biográfica encontram sua razão de ser na clínica que, cá e acolá, nos oferta pacientes que bem ilustram uma ou outra e, desta maneira, parecem dar conta de aspectos simultâneos e inerentes ao que chamamos estrutura esquizofrênica. Ainda assim, estamos distantes de uma maturidade psicopatológica no que se refere à esquizofrenia. Os estudos fenomenológicos encontram-se longe de estarem esgotados e há diversos aspectos negligenciados pela tradição, sendo a endogeneidade apenas um deles.

Assim como a melancolia e a mania, a esquizofrenia é uma psicose paradigmaticamente associada ao campo endógeno, mas, como tal, não foi objeto de grande investigação fenomenológica. É exatamente sobre as relações entre endogeneidade e esquizofrenia que serão tecidas as considerações que se seguem, de caráter preliminar, avessas a uma nivelação da complexidade do objeto psicopatológico em questão a postulados esquemáticos e definitivos.

A palavra endógeno, tão prosaica na literatura psicopatológica, é um protótipo de imprecisões e deslizamentos conceituais, tão corriqueiros no campo epistemológico da psicopatologia. “ 'Endógeno' significa 'nascido dentro' e foi incorporado do léxico botânico ao psiquiátrico em 1892, por Moebius, para marcar a condição de oposição ao exógeno" (Tellenbach, 1969, p. 29, Berrios, 1987, p. 494). Segundo Berrios, a distinção poderia ter morrido silenciosamente se não fosse pela sua 'infeliz' inclusão no manual psiquiátrico de Kraepelin, em 1896. Ao criador da dementia praecox, teria interessado justamente o caráter inespecífico e abstrato do conceito de endogeneidade, atrelado à uma entidade interna pouco delimitada (Berrios, 1987, p. 495). 
A dicotomia endógeno-exógeno sobreviveu na psicopatologia do começo do século $\mathrm{XX}$, sobretudo na apreciação das psicoses em âmbito causal: como endógenas são adjetivadas aquelas decorrentes de causas "internas" à mente, enquanto exógeno qualifica os quadros psicopatológicos que emergem de alterações somáticas visíveis e conhecidas, ou seja, causas "externas" à mente, mas não necessariamente ao corpo (Schneider, 1978, p.149-150). Como mostra Messas (2013), tal distinção, que remete ao dualismo ontológico, marcará presença em grande parte da literatura clássica, ainda que de forma "nebulosa e negativa" (no sentido daquilo que não sabemos).

Para autores como Kurt Schneider, que produziram sua obra psicopatológica imbuídos de certo otimismo no progresso científico, os avanços tecnológicos haveriam de elucidar o substrato somático das distintas alterações psicopatológicas e, desta maneira, extinguiriam o rol das psicoses endógenas (Schneider, 1978). Talvez em parte por essa razão, muitos autores omitiram um exame mais profundo da categoria, resignando-se a negatividade da qualificação, talvez simplesmente se contentando em aguardar o "prometido" fim do termo. O termo acabou banido da nomenclatura psiquiátrica contemporânea, por outra razão, como mostra Messas (2013, p .6-7):

Podemos aqui postular o arrefecimento do uso dos adjetivos endógenoexógeno na histórica do sucesso do dualismo ontológico. Como não se identifica alguma solução simples para a região das endogeneidades, e esta se liga diretamente ao insucesso da psiquiatria somática em absorver para si todo o 
Considerações fenomenológicas sobre o conceito de endogeneidade na esquizofrenia

campo das causas das doenças e transtornos mentais, resolve-se, por um golpe de caneta, entronizar o dualismo como estratégia vencedora. O método para a obtenção dessa vitória foi a exclusão dos termos que denunciavam sua fraqueza. Decide-se que o dualismo é vencedor e relega-se ao ostracismo as categorias que The incomodam. Pela mesma lógica, podemos dizer que os conceitos do setor endógeno se preservam no cotidiano clínico porque neste, diante dos pacientes, não se pode tomar como dada a suposta vitória incontestável do dualismo.

Foi Tellenbach quem, na segunda metade do século passado, interessado na patogênese da melancolia, remediou, em parte, a ausência de reflexão sobre a endogeneidade na literatura psicopatológica. Na obra Melancholie (1974), a partir do "comércio direto" com pacientes melancólicos, ele buscou a positividade desta "terceira zona causal", de aspecto criptógeno. Entretanto, a esse autor interessava fundamentalmente naquele momento a delineação de um tipo, o typus melancholicus que, por força do endógeno, posta-se no mundo caracteristicamente em condições pré-melancólicas. Tais pretensões patogenéticas ofuscaram, de certo modo, a própria investigação fenomenológica da endogeneidade, tema que indiscutivelmente mereceria uma elaboração contundente e abrangente.

Do ponto de vista do método, esse enfrentamento fenomenológico exige que se atenha àquilo que é imanente à consciência (Binswanger, 1973, p. 25), aos fenômenos per se e, assim sendo, no tocante à endogeneidade, propõe-se a conhecer as distintas modalidades de sua projeção na experiência consciente. 
Ou seja, a natureza não mais vinculada apenas como origem remota, mas como força continuamente presente no campo vivencial, ainda que de modo heterogêneo. Esta complexa observação, da qual se incumbe a vertente fenomenológica por vocação, abarcaria o delineamento do quinhão inegociável da natureza nas infindas possibilidades individuais, das tendências estáveis e modalidades de aparição do endógeno na consciência, assim como das suas possibilidades de malogro, estas as mais marcadas pelas tintas da endogeneidade.

A conjuntura patológica, definida pela "imobilidade de formas de manifestação típicas" (Tellenbach, 1976, p. 34), constituiria uma ocasião privilegiada para contemplar as caricaturas do endógeno e a perspectiva essencialista, um caminho natural para o desvelamento dos predicativos típicos, universais e impessoais do fenômeno endógeno. Sobre essa perspectiva de investigação, Binswanger já afirmava em seu manifesto sobre a fenomenologia que o método desta consistia no "caminho pelo qual se chega, passo a passo, do fato isolado empírico individual à essência supra-empírica ou pura" (Binswanger, 1973, p. 32). E que, apesar do exercício reflexivo da psicopatologia se equilibrar nas inesgotáveis transições entre as esfera dos fatos e das essências, haveria legitimidade na filiação fenomenológica da psicopatologia, mesmo que nunca fosse possível alcançar as "alturas da essência pura", sua universalidade absoluta (Binswanger, 1973, p. 29).

A investigação pioneira da endogeneidade, feita por Tellenbach, já se propunha, por meio de uma "contemplação intuitiva", a discriminar os 
Considerações fenomenológicas sobre o conceito de endogeneidade na esquizofrenia

elementos que dariam testemunho da "índole especial" desta "entidade própria" (Tellenbach, 1976, p. 34). Ele buscava "restituir um valor positivo autêntico" ao campo original do Endon, de cuja metamorfose seria o que denominamos psicose endógena (Tellenbach, 1976, p. 35; p. 61; Tatossian, 2006, p. 184). Como facetas próprias à instância endógena figuram a ligação aos ritmos fundamentais (alternância vigília/sono, ciclo reprodutivo), os fenômenos próprios da cinese vital, a vinculação a fases de maturação, a expressão de caráter global (na totalidade) e a reversibilidade de princípio.

Tais atributos atestariam a presença endógena na vigência da melancolia, porém Tellenbach é contundente em apontar que o endógeno debutaria muito antes, atrelado à origem do typus melancholicus. Neste, duas situações específicas de fragilidade, a remanência e a includência, deflagrariam um "chamado" a essa natureza que, ao entrar em cena, em um salto "misterioso" conduziria a estrutura a uma deformação fixa e típica que lhe corresponde. Assim, para Tellenbach a natureza endógena responde tanto pela tipicidade do modo de implantação do typus melancholicus no mundo, como pela modificação abrupta do perfil de habitualidade da estrutura psíquica, que desemboca em uma nova forma temporoespacial, a qual se denomina melancolia.

Neste momento, abre-se um pequeno parêntese para considerar o sentido aqui empregado de estrutura psíquica e suas implicações em relação à natureza. Por estrutura, entende-se o feixe de coordenadas temporoespaciais, garantia da aparição de qualquer fenômeno, patológico ou não, no plano da experiência tal como é dada ao conhecimento da própria consciência (Messas, 
2004). No contexto da patologia, aproxima-se de uma forma primordial, ou seja, da noção de essência, como vista nas obra de autores como Minkowski, entretanto o conceito também deve ser apreciado sob a perspectiva de mobilidade, como uma estabilidade dialética (Messas, 2012). A natureza, como já foi dito, deve ser considerada como uma força presente continuamente no campo da consciência, "aquilo que preme, que se sobrepõe e subjaz à história de vida ou às ordenações da vontade", um "modo habitual de pressão, que exatamente por essa constância, acaba por exercer um papel decisivo no desabrochar vital" (Messas, 2010, p. 97). Em relação à estrutura, pode "forçar seus limites formais ora para um lado ora para outro" (Messas, 2010, p. 97)

Assim, torna-se crucial a indagação das articulações entre natureza endógena e estrutura psíquica. Essas instâncias podem se comportar sinérgica ou antagonicamente, mas sobretudo compõem um equilíbrio dialético. A estrutura pode fazer valer a sua porção estável como dique, contendo, possivelmente não de maneira solitária, o possível exercício prepotente da natureza. Quando neste balanço de forças a natureza triunfa sobre a forma básica ou, dito de outra forma, quando a pressão endógena é tão pungente sobre o perfil estrutural que acaba por deformá-lo, há a emergência de uma figura essencial da natureza que, dependendo da silhueta fundamental, será reconhecida como melancolia, esquizofrenia etc (Messas, 2010, p. 98).

Essa heterogeneidade estrutural, imposição abrupta e tirânica de uma nova forma, dissolve o estilo habitual de articulação da consciência com o mundo e restringe o exercício da livre decisão. Do ponto de vista da estrutura, 
Considerações fenomenológicas sobre o conceito de endogeneidade na esquizofrenia

essa "entrada em cena" do endógeno pode ser determinada por meio de três índices, como aponta Messas (2013): 1- A desestruturação da articulação primordial entre consciência e mundo, ou seja, o corrompimento do "polo dual histórico de relação", "a raiz mais sólida de manutenção do sentido da estrutura da consciência (Binswanger, 1957) e, em termos prospectivos, 2- o impedimento da restruturação da articulação típica da estrutura e a 3- "autonomização de zonas da estrutura da consciência, configurando o caráter patológico, quando a lógica de sentido do individuo é substituída pela lógica da doença" (Messas, 2013).

Assim, as psicoses endógenas são expressões de um ataque ao ponto capital da implantação da consciência no mundo e, quanto maior for a intensidade ou a recorrência do período de protagonismo endógeno, maior a tendência de autonomia patológica, até o extremo no qual a natureza assumiria a titularidade do devir. Deste modo, a psicopatologia das psicoses endógenas deve, necessariamente, trafegar por meio do intrincado rendilhado de possibilidades de desfechos na contínua negociação entre natureza, estrutura psíquica e anseios do eu.

Deve-se notar que a perspectiva essencialista foi apresentada em dois contextos diferentes, sendo o primeiro relacionado à redução das apresentações psicopatológicas a um núcleo fundamental no âmbito da estrutura vivida. É a razão de ser de grande parte da literatura fenomenológica, que reconhece como inerente ao humano desequilíbrios nas condições de possibilidade da consciência, que se expressam sob formas regulares e típicas, ainda que, 
evidentemente, sujeitas à refratariedade própria da sua implantação no singular. É plausível supor, como já foi dito, que haja múltiplas essências (as quais correspondem as distintas patologias endógenas) que difiram, por exemplo, no ponto de ataque e no tamanho do dano à consciência implantada no mundo. Ainda assim, as essências continuariam sendo endógenas. Isso remete ao segundo contexto, que nomearemos essência da endogeneidade: trata-se dos predicativos intrínsecos do Endon, instância detentora da unidade formal específica e da possibilidade de expansão e transformação da mesma.

As psicoses endógenas, a grosso modo alterações do desdobramento entelequial da estrutura, ao menos em algum momento, explicitariam os elementos do campo original. Dentre eles, os elementos apontados por Tellenbach e já citados: a ligação às modalidades de ritmos básicos e à cinese vital, a vinculação a fases de maturação, a expressão de caráter global e a reversibilidade de princípio, aos quais corresponderiam fenômenos como a insônia, estagnação do devir, cisão da globalidade homogênea e reversibilidade, presentes na apresentação da patologia melancólica.

No caso da melancolia, em virtude do caráter fásico da patologia (conceitualmente, fases são alterações incompreensíveis e reversíveis, uma das séries típicas de curso biográfico - Jaspers, 2000), a coincidência temporal das essências da endogeneidade e da melancolia leva Tellenbach a justificar o comportamento biográfico da patologia (da essência melancólica, portanto) através da reversibilidade de princípio própria da endogeneidade. Ou seja, subordina a vigência da patologia aos elementos próprios da essência da 
Considerações fenomenológicas sobre o conceito de endogeneidade na esquizofrenia

endogeneidade, o que, como pode se supor, torna-se problemático no caso da esquizofrenia.

Seria a reversibilidade inerente à ação endógena a única alternativa de entendimento da melancolia enquanto fase biográfica? Supondo que não, a alternativa seria encontrar subsídios em outro domínio, ou seja, na estrutura (o que equivale a dizer em outra essência, a melancólica). A estrutura melancólica parece ser de natureza mais benigna que a dita esquizofrênica, fundamentalmente em virtude da temporalidade que, apesar da magnitude do dano, ainda retém de maneira intrínseca a possibilidade de reversão à forma “original" (ao que correspondem as observadas remissões espontâneas). Além disso, ainda que haja um salto qualitativo deflagrado pela endocinese, o bloqueio do devir da melancolia guarda relações de certa continuidade com o privilégio das instâncias retentivas e a falta de vocação para uma experiência de protensão alargada próprias ao typus melancholicus e à remanência, o que, em tese, pode facilitar a transição de uma forma a outra. Outros elementos da melancolia, como espacialidade e interpessoalidade, também corroborariam essa hipótese, mas seu detalhamento foge ao escopo deste trabalho.

De qualquer modo, se assim for, o comportamento fásico da melancolia seria inerente à sua estrutura, liberando-se, por assim dizer, a responsabilidade dos predicativos da essência da endogeneidade no curso da patologia (haveria uma coincidência de comportamento "reversível" de ambas as essências, justificadas internamente por cada uma). Era justamente aqui, como foi dito, que residia uma das fragilidades da concepção de Tellenbach que, ainda que 
não titubeasse em inserir a esquizofrenia no rol endógeno, precisou remeter às catatonias periódicas, pouco paradigmáticas da ideia de esquizofrenia, para conciliar o curso da patologia e a reversibilidade do endógeno. Tellenbach também passa ao largo de outro ponto problemático que seria a dessemelhança entre as alterações de ritmos vitais, muito mais atrelados à vigência das fases melancólicas do que ao curso esquizofrênico.

De qualquer modo, aos períodos de grande diligência endógena, tipicamente vinculados à fases de maturação, estariam reservados os atributos descritos por Tellenbach, como uma de-sincronização pronunciada de ritmos e uma alteração de cinese a mais vital possível (quase próxima a um estupor vital). A respeito da modificação da cinese, a alusão mais enfática à endogeneidade na esquizofrenia, Tellenbach, afirma: “Dos diversos quadros nos quais estão suprimidas a unidade da cinese do acontecer vital, observa-se isso, de modo mais impressionante, nas psicoses esquizofrênicas" (Tellenbach, p. 54). Ele faz menção à "inibição do movimento vital básico" de Gebsattel (1954), a uma "decadência da vitalidade" que pode ser compreendida a partir da corrupção do mais primordial impulso de vida. Parece pertinente perguntar se, no caso de uma interdição contínua dessa ordem, restaria alguma possibilidade de movimento histórico (lembrando que a tradição reconhece a esquizofrenia como forma fundamentalmente biográfica, distintas da mania e melancolia). Novamente, a chave da questão pode estar na separação entre estrutura psíquica e natureza, dito de outra forma, no postulado de um malogro do devir por imposição primária da natureza e de outro por consequência da 
Considerações fenomenológicas sobre o conceito de endogeneidade na esquizofrenia

desarticulação temporal. A modificação da cinese vital própria da essência da endogeneidade remeteria à potência mais elementar da existência, ao enfraquecimento do elã vital, que naturalmente perpassaria a totalidade da existência e cuja supressão definitiva equivaleria à própria morte. Entretanto, a viabilidade restrita de movimentação autêntica das formas esquizofrênicas também pode ser justificada pela permanência de uma forma hiper-estável e enrijecida, a essência da patologia. Assim, a estrutura esquizofrênica interditaria, por razões intrínsecas, um desdobrar ordenado da existência, ainda que haja propulsão vital endógena (como consequência fenomênica, teríamos, por exemplo, o autismo rico e os atos em curto circuito - Minkowski, 2000). De maneira semelhante, no que se refere a outra característica própria da endogeneidade, sua expressão na totalidade, a estrutura esquizofrênica também pode ser invocada como justificativa do caráter global da patologia e a sua apreensão intuitiva (praecox feeling) (Tellenbach, 1976, Rumke).

Desta maneira, como foi visto, a essência da endogeneidade se faria presente de modo intermitente, apenas nos momentos de protagonismo da natureza, que, na esquizofrenia, pode se supor ocorrer no prelúdio das manifestações sintomáticas explícitas da patologia, uma vez que estas são antecedidas pela transformação estrutural (que inclusive pode ser mais insidiosa e diluída no percurso temporal) e nos períodos de exacerbação, conhecidos como "surtos". Essa heterogeneidade de atividade da natureza dependeria de fatores inerentes a ela mesma, estruturais ou situacionais, dentro de um complexo balanço de forças, citado anteriormente (Tamelini, 2012). 
Diferentemente da investida endógena própria da melancolia, no caso da esquizofrenia, mesmo uma solitária atuação da natureza tende a ser condição suficiente para a presença da essência esquizofrênica a longo prazo (Tamelini, 2012). Ou seja, ainda que a atuação endógena seja reversível por princípio, as suas decorrências estruturais não são necessariamente. Essa permanência, de magnitude espectral é verdade, tem como correlato a evolução processual da patologia (na acepção jasperiana, alterações incompreensíveis e irreversíveis) (Jaspers 2000; Tamelini, 2013). Portanto, a essência esquizofrênica remete como origem à natureza que lhe é correspondente (período ao qual corresponderia a essência da endogeneidade), mas fundamentalmente é o resultado de uma modificação capital dos fundamentos apriorísticos da consciência (das proporções antropológicas de temporalidade, espacialidade, corporeidade e interpessoalidade), um novo equilíbrio formal obtido após uma ou sucessivas intervenções endógenas. Essa essência, que evidentemente se confunde com a própria noção de esquizofrenia trabalhada por autores como Minkowski e Blankenburg, é a grande razão de ser da patologia como forma clínica que conhecemos.

A clínica da esquizofrenia não se resume a apreciar o desenho estático da essência esquizofrênica, mas a percutir continuamente o campo da complexa dialética entre dinâmica irruptiva da natureza endógena e "intencionalidade estabilizadora" da estrutura (Janzarik (1959) in Blankenburg, 2013, p. 30), que pode se tornar ainda mais imprevisível e delicado uma vez inaugurada a patologia. Também não se deve negligenciar que a estrutura psíquica é uma 
Considerações fenomenológicas sobre o conceito de endogeneidade na esquizofrenia

forma móvel que, mesmo sob o duro fardo da inelasticidade esquizofrênica, pode exibir propósitos de movimentação iso e até anisomórficos (Messas, 2010).

Vale ressaltar também que o caráter processual da esquizofrenia não está em questão neste trabalho. Há alguns questionamentos a respeito do quão fatalista poderia ser esta concepção biográfica (Ciompi, 1980), sobre os quais Tatossian comenta: “Ciompi então se perguntou se a esquizofrenia crônica não é um artefato e, seguido de Zubin e Steinhauer, pode-se estimar que a doença esquizofrênica não é uma doença com episódios, mas consiste nestes episódios" (Tatossian, 2012, p. 137-138). Por um lado, essas colocações poderiam se aproximar do que foi aqui postulado, ao fazerem inferência a uma atividade endógena de expressão fásica, por outro, no presente artigo, tenta-se justamente dar sustentação ao processo esquizofrênico, que não parece ser um construto datado (Daker, 2014), a partir das tendências próprias da essência esquizofrênica.

Por fim, uma menção en passant sobre a importância da continuidade e aprofundamento dos estudos do campo da endogeneidade na pesquisa psicopatológica. O reconhecimento da essência da endogeneidade poderia ser um indicador da oportunidade (ou necessidade?) de utilização de terapêuticas farmacológicas (Ledoux, 2014), ainda que precisemos antes especificar do que consiste uma terapia antipsicótica do ponto de vista da essência estrutural, campo praticamente inexplorado na psicopatologia fenomenológica. Do mesmo modo, as psicoterapias que se constituem em meio ao balanço entre a essência esquizofrênica e o "remanescente da personalidade do indivíduo" também 
devem considerar que o percurso singular de um esquizofrênico é de muitas maneiras permeado pelos contornos da natureza. No caso individual, sempre coexistiriam zonas de profunda alteração da temporalização e zonas de recrudescimento e projeção histórica, zonas de imposição e livre arbítrio e, deste modo, a clínica da esquizofrenia consistiria do manejo das dissonâncias impositivas da natureza, a partir do seu pronto reconhecimento e da tentativa de retomada da melodia tonal da estrutura, ainda que sob o duro fardo de uma endogeneidade que pode, a qualquer momento, tomar de assalto a existência.

\section{Conclusão}

A endogeneidade, tal como apresentada por Tellenbach, pode ser investigada pela perspectiva fenomenológica-eidética. Como atributos da essência da endogeneidade figurariam, dentre outros, a alteração de ritmos vitais, a modificação da cinese vital e a reversibilidade. A presença de tais elementos apontaria para um período de grande protagonismo da natureza, cujo resultado poderia ser a modificação estrutural da consciência. A essência esquizofrênica é conhecida pelo seu engessamento temporoespacial, em um arranjo típico das formas deficitárias, assim como pelo confisco drástico de grande parte dos designíos de expansão e livre determinação. A partir desta distinção entre natureza e estrutura, algumas considerações preliminares foram apresentadas e estas devem servir sobretudo como estímulo para o aprofundamento das investigações psicopatológicas e terapêuticas no âmbito da esquizofrenia. 
Considerações fenomenológicas sobre o conceito de endogeneidade na esquizofrenia

\section{Referências bibliográficas}

Blankenburg, W. (1982) A dialectical conception of anthropological proportions. In: De Koonig, A. Jenner, F., editors. Phenomenology and Psychiatry (p. 3550). London: Academic Press.

Blankenburg, W. (2013) "La pérdida de la evidencia natural”. Santiago do Chile. Ediciones Universidad Diego Portales .

Berrios, G. (1987) “Historical aspects of psychoses: 19th century issues". British Medical Bulletim, 43 (3), p. 484-498.

Binswanger, L. (1957) Schizophrenie. Pfullinger: Günther Neske Verlag.

Binswanger, L. (1968) El caso Ellen West: estúdio antropológico-clínico. In: Existencia. Nueva Diménsion en Psiquiatria y Psicología. Madrid: Editorial Gredos.

Binswanger, L. (1973) Sobre Fenomenologia. In: Artículos y conferencias, p 15-45. Artículos y conferencias escogidas. Madri: Editorial Gredos.

Binswanger, L. (2012) O caso Suzanne Urban - Psicopatologia Fenomenológica Contemporânea, 1 (1), 198-344.

Ciompi, C. (1980) Catamnestic long-term study on the course of life and aging of schizophrenics. Schizophrenia Bulletin, 6(4), 606-618.

Daker, M. (2014) Validade do conceito de psicose processual. Psicopatologia Fenomenológica Contemporânea, 3 (2), 1-15.

Dörr Zegers, O. (1995) Psiquiatría Antropológica: contribuciones a una psiquiatría de orientación fenomenológica-antropológica. Santiago de Chile: Universitária.

Jaspers, K. (2000) Psicopatologia Geral. São Paulo: Editora Atheneu.

Ledoux, A., Cioltea, D. Angeletti, L. (2014) Une approche clinico-phénoménologique des dépressions résistantes. L'Encéphale (2014) 40, 168-173.

Messas, G. (2004) Psicopatologia e Transformação: um esboço fenoîmeno-estrutural. São Paulo: Casa do Psicólogo.

Messas, G. (2010) Ensaio sobre a estrutura vivida. São Paulo: Roca. 
Messas, G. (2012) A noção de estrutura na psicopatologia/psicologia fenomenológica. Uma perspectiva epistemológica. In: "Psicopatologia Conceitual", de Rodrigues A, Streb L, Daker M, Serpa O. Editora Roca.

Messas, G. (2013) Sentido e limites do diagnóstico diferencial entre psicoses endógenas e exógenas. In: Revista de Psicopatologia Fenomenológica Contemporañea, 2(1), 2-15.

Minkowski, E. (2000) La Esquizofrenia: psicopatologia de los esquizóides y los esquizofrénicos. México, D. F.: Fondo de Cultura Económica.

Minkowski, E. (2005) Le temps vécu. Études Phénoménologiques et Psychopathologiques. Paris, PUF.

Schneider, K. (1978) Psicopatologia Clínica. 3 ed. Mestre Jou, São Paulo.

Tamelini, M. G. (2013) O Processo Psíquico sob a ótica Fenomenológica. Psicopatologia Fenomenológica Contemporañea, 2 (1), 91-102.

Tamelini, M. G. (2012) Cinética Estrutural na Esquizofrenia. Psicopatologia Fenomenológica Contemporânea, 1, 3-25.

Tatossian, A. (2006) A Fenomenologia das Psicoses. São Paulo: Escuta.

Tatossian, A. \& Moreira, V. (2012) Clínica do Lebenswelt: Psicopatologia e Psicoterapia Fenomenológica. São Paulo: Editora Escuta.

Tellenbach, H. (1969) Estudios sobre la patogénesis de las perturbaciones psíquicas. México DF: Fondo de Cultura Económica.

Tellenbach, H. (1975) La Melancolia. Visión histórica del problema: tipologia, patogenia y clinica. Madrid, Ed. Morata. 